\title{
ADSORPTION OF M(II) (M = Mn, Cu, Zn) IN VARIOUS pH AND CONTACT TIME USING CHITOSAN-SILICA PREPARED BY SOL-GEL METHOD
}

\author{
Darjito", M. M. Khunur, D. Purwonugroho, M. A. Yuliantari, Z. R. Sari, \\ L. H. A. K. Suryaningrat and Y. P. Prananto \\ Department of Chemistry, Brawijaya University, Malang-65145, Indonesia \\ *E-mail: darjito@ub.ac.id
}

\begin{abstract}
Chitosan-silica prepared by sol-gel method was used for adsorption of $\mathrm{M}(\mathrm{II})\left(\mathrm{M}=\mathrm{Mn}^{2+}, \mathrm{Cu}^{2+}, \mathrm{Zn}^{2+}\right)$ in solution at room temperature. The prepared chitosan-silica was characterized by Fourier Transform Infrared (FTIR) and Scanning Electron Microscopy (SEM). Effect of $\mathrm{pH}$ of the metal solution and adsorption contact time toward the adsorption capacity were investigated. The correlation between M(II) concentrations and the adsorption capacity, which was determined at optimum $\mathrm{pH}$ and optimum adsorption contact time, is also discussed. FTIR and SEM results are identical to that of chitosan-silica reported previously. Chitosan-silica performs the highest adsorption capacity for $\mathrm{Cu}^{2+}, \mathrm{Mn}^{2+}$, and $\mathrm{Zn}^{2+}$, successively. The optimum $\mathrm{pH}$ for $\mathrm{Mn}^{2+}, \mathrm{Cu}^{2+}$ and $\mathrm{Zn}^{2+}$ adsorptions were obtained at $\mathrm{pH}$ 5. It is suggested that due to the combination of ionic size and HSAB concept, $\mathrm{Cu}^{2+}$ gives the highest adsorption capacity than that of $\mathrm{Mn}^{2+}$ and $\mathrm{Zn}^{2+}$. The optimum contact time for $\mathrm{Mn}^{2+}$ and $\mathrm{Cu}^{2+}$ adsorption was obtained at 75 minutes with adsorption capacities of $6.56 \pm 0.04 \mathrm{mg} / \mathrm{g}$ and $15.46 \pm 0.02 \mathrm{mg} / \mathrm{g}$, respectively, whereas $\mathrm{Zn}^{2+}$ adsorption was obtained at 60 minutes with an adsorption capacity of $5.01 \pm 0.12 \mathrm{mg} / \mathrm{g}$.
\end{abstract}

Keywords: Chitosan-Silica, Adsorption Capacity, pH, Contact Time, Sol-Gel.

(c) RASĀYAN. All rights reserved

\section{INTRODUCTION}

Chitin, which mainly extracted from the skins of crustaceans and molluscs, is the second most abundant natural biopolymer. Chitin can be transformed into chitosan by deacetylation process. The conversion of chitin into chitosan make this renewable biomaterial have better versatility due to its solubility. Chitosan is insoluble in water but soluble in organic acids. ${ }^{1}$ Chitosan, polymeric (2-amino-2-deoxy- $\beta$ - $(1,4)$-Dglucopyranose, is copolymer of a $(1,4)$-glucosamine $\left(\mathrm{C}_{6} \mathrm{H}_{11} \mathrm{O}_{4} \mathrm{~N}\right)_{\mathrm{n}}$ that has different number of $\mathrm{N}$-acetyl group. ${ }^{2}$ Chitosan can also be considered as a linear polyamine with reactive amino $\left(-\mathrm{NH}_{2}\right)$ groups and some reactive hydroxyl (-OH) groups, thus it has chelating ability for transition metal ions. ${ }^{3}$

Chitin and chitosan (Fig.1) have many applications and were widely utilized. Particularly as an adsorbent in the separation technologies, chitosan has been widely explored for adsorption of metal ions, dyes, and other organic pollutants in the solution due to its chelating ability and functional groups. ${ }^{4}$ Although chitosan can be used directly, some researchers prefer to modify it through the glucosamine unit to enhance its adsorption capacity and recovery. Each modification has its own characteristic and was made for certain purposes. Kyzas and Bikiaris summarised published studies (during 2012-2014) of modified chitosan for adsorption of dyes and metal ions including their adsorption capacity. ${ }^{5}$ There are two main modifications of chitosan, namely by grafting (functional group insertion) or by cross-linking reaction (combining with the macromolecular unit), such as zeolite, ${ }^{6-7}$ polyvinyl alcohol, ${ }^{8}$ graphite oxide, ${ }^{9}$ alumina $,{ }^{10} 3,4,5$-trihydroxy benzoic acid, ${ }^{11}$ trimethylamine sulphur trioxide,${ }^{12}$ silica, ${ }^{13-15}$ cellulose acetate ${ }^{16}$ etc. Many of these modifications resulting in adsorbent with better adsorption capacity and durability in extreme conditions. In this study, we are utilizing chitosan modified with silica made by sol-gel method for adsorption of transition metal ions in the solution. Silica is a good adsorbent for metal ions due to its cross-linking $\mathrm{Si-O}-\mathrm{Si}$ structure. Silica is abundant natural resources, relatively harmless and can be

Rasayan J. Chem., 12(3), 1485-1492(2019)

http://dx.doi.org/10.31788/RJC.2019.1235220

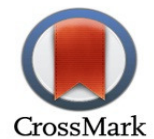


prepared from a range of silica rich-natural resources, such as mud and rice husk. ${ }^{17-19}$ Synthesis and properties of chitosan-silica was reported several times, including their adsorption for metal ions. ${ }^{13,15,17-21}$ However, their adsorption studies, specifically for first-row transition metal ions (except Zn(II) reported by Mahatmanti ${ }^{19}$ ) have not been explored intensively, hence we decided to focus on these metal ions.

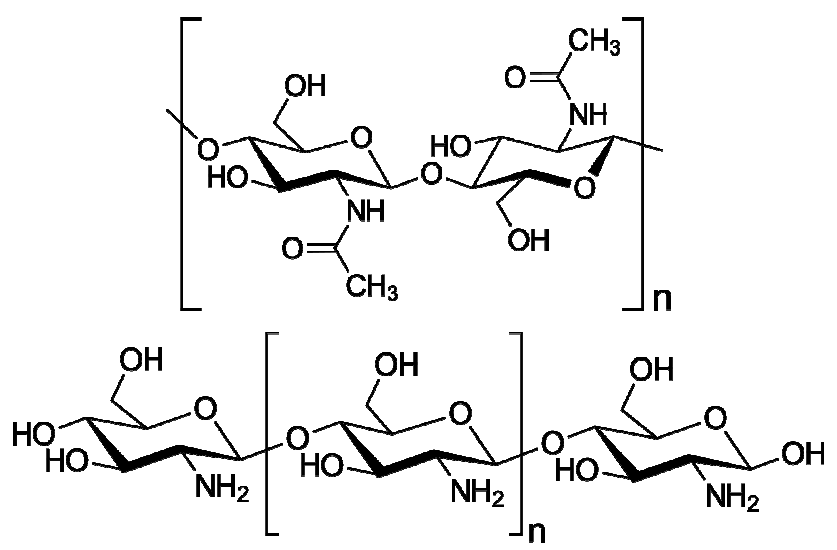

Fig.-1: Structures of Chitin (Top) and Chitosan (Bottom)

Particularly, $\mathrm{Mn}^{2+}, \mathrm{Cu}^{2+}$, and $\mathrm{Zn}^{2+}$ were chosen to represent the first-row transition metal because these metal ions are frequently found in the aquatic system and produced as industrial waste. These three ions also have different chemical properties hence studying these three ions will give a general overview of the adsorption study of the first-row transition metals. Although the ionic radius of $\mathrm{Mn}^{2+}, \mathrm{Cu}^{2+}$, and $\mathrm{Zn}^{2+}$ are insignificantly different $\left(70,73\right.$, and $74 \mathrm{pm}$, respectively ${ }^{22}$ ), these ions have a different level of softness/hardness. Based on Hard Soft Acid-Base (HSAB) concepts theorised by Pearson, $\mathrm{Mn}^{2+}$ is grouped as a hard acid, $\mathrm{Cu}^{2+}$ is a borderline acid, and $\mathrm{Zn}^{2+}$ is a soft acid. ${ }^{23}$ Different level of softness influence the interaction strength between the metal ion (act as acid) and the adsorbent functional groups (act as a base). These ions are very soluble in aqueous solution and can be precipitated as their hydroxide in different $\mathrm{pH}\left(\mathrm{Ksp} \mathrm{Mn}(\mathrm{OH})_{2}=2 \times 10^{-13}, \mathrm{Cu}(\mathrm{OH})_{2}=2 \times 10^{-19}, \mathrm{Zn}(\mathrm{OH})_{2}=5 \times 10^{-17}\right){ }^{22} \mathrm{In}$ addition, $\mathrm{Mn}^{2+}$ tends to form octahedral complexes, whereas $\mathrm{Cu}^{2+}, \mathrm{Zn}^{2+}$, respectively, are more likely forming complex compounds with lower coordination numbers, such as square planar or tetrahedral.

In order to optimize the chitosan-silica adsorption capacity and durability in extreme condition so that it can be applied for an actual sample and real situation, influential factors such as $\mathrm{pH}$, contact time, adsorbent and/or metal ion concentrations, temperature, etc. should be incorporated and investigated. The works reported here is an initial stage of the development of chitosan-silica for transition metal ions adsorbent, in which the optimization was based on the $\mathrm{pH}$ of the metal ion solution and contact time. Both factors are crucial in the first stage of adsorption studies and will give basic information and hints for the remaining stages.

\section{Materials}

\section{EXPERIMENTAL}

$\mathrm{MnCl}_{2}, \mathrm{CuCl}_{2} \cdot 2 \mathrm{H}_{2} \mathrm{O}, \mathrm{ZnCl}_{2}, \mathrm{CH}_{3} \mathrm{COOH}, \mathrm{HCl}, \mathrm{NaOH}$, chitosan, and $\mathrm{Na}_{2} \mathrm{SiO}_{3} 6 \%(\rho=1.35 \mathrm{~g} / \mathrm{mL})$ were used without further purification and were all obtained from Merck.

\section{Preparation and Characterization of Chitosan-Silica}

Chitosan $(1 \mathrm{~g})$ was dissolved in $80 \mathrm{~mL}$ of $\mathrm{CH}_{3} \mathrm{COOH} 2 \%(\mathrm{v} / \mathrm{v})$. The solution was added with $100 \mathrm{~mL}$ $\mathrm{Na}_{2} \mathrm{SiO}_{3} 6 \%(\mathrm{v} / \mathrm{v})$ while stirring. The formed sol-gel was dried in an oven at $105{ }^{\circ} \mathrm{C}$ for $30 \mathrm{~min}$. The solgel then washed with distilled water (up to $\mathrm{pH}$ that equal to the $\mathrm{pH}$ of distilled water). After that, the solgel was placed back in the oven and dried at $105{ }^{\circ} \mathrm{C}$ for several hours, then it was cooled down to room temperature. Next, the dried chitosan-silica was ground in a mortar and sieved using a 200-mesh size resulting in a fine powder (yield $=2.83 \mathrm{~g}$ ). The powder then characterized by Fourier Transform Infrared (FTIR) and Scanning Electron Microscopy (SEM). 


\section{Determination of Optimum pH}

Series of $\mathrm{Mn}^{2+}, \mathrm{Cu}^{2+}$, and $\mathrm{Zn}^{2+}$ solutions (40 ppm, $25 \mathrm{~mL}$ ) in various $\mathrm{pH}(3,4,5,6)$ were prepared in a $100 \mathrm{~mL}$ Erlenmeyer flask. Into each solution, $0.1 \mathrm{~g}$ chitosan-silica was added and the solution was shaken using automatic shaker at room temperature for 30 minutes with a rate of $125 \mathrm{rpm}$. Next, the solution was filtrated using Whatman paper no 41 . A $1 \mathrm{~mL}$ filtrate was transferred and diluted with water into $10 \mathrm{~mL}$ in a volumetric flask. This solution is then used for Atomic Adsorption Spectrophotometry (AAS) analysis to determine the concentration of the metal ion after adsorption. This procedure was performed three times for each $\mathrm{pH}$. The optimum $\mathrm{pH}$ was determined based on the $\mathrm{pH}$ that gives the highest adsorption percentage. The optimum $\mathrm{pH}$ was then used in the next stage.

\section{Determination of Optimum Adsorption Contact Time}

Series of $\mathrm{Mn}^{2+}, \mathrm{Cu}^{2+}$, and $\mathrm{Zn}^{2+}$ solutions (40 ppm, $25 \mathrm{~mL}$ ) at optimum $\mathrm{pH}$ were prepared in a $100 \mathrm{~mL}$ Erlenmeyer flask. Into each solution, $0.1 \mathrm{~g}$ chitosan-silica was added and the solution was shaken using automatic shaker at room temperature with the rate of $125 \mathrm{rpm}$ in various contact time $(15,30,60$, and 75 minutes). The 30 min contact time data was obtained from the determination of $\mathrm{pH}$ optimum (previous stage). Next, the solution was filtrated using Whatman paper no 41 . A $1 \mathrm{~mL}$ filtrate was transferred and diluted with water into $10 \mathrm{~mL}$ in a volumetric flask. This solution is then used for AAS analysis to determine the concentration of the metal ion after adsorption. This procedure was performed three times for each contact time. The optimum adsorption contact time was determined based on the contact time that gives the highest adsorption percentage. The optimum adsorption contact time was then used in the next stage.

\section{Correlation of $\mathrm{M}(\mathrm{II})$ Concentration and the Adsorption Capacity}

Series of $25 \mathrm{~mL} \mathrm{Mn}^{2+}, \mathrm{Cu}^{2+}$, and $\mathrm{Zn}^{2+}$ solutions in various concentration (20, 40, 80, and $200 \mathrm{ppm}$ ) were prepared in a $100 \mathrm{~mL}$ Erlenmeyer flask at optimum $\mathrm{pH}$. Into each solution, $0.1 \mathrm{~g}$ chitosan-silica was added and the solution was shaken using automatic shaker at room temperature with a rate of $125 \mathrm{rpm}$ at optimum adsorption contact time obtained in the previous stage. Next, the solution was filtrated using Whatman paper no 41. A $1 \mathrm{~mL}$ filtrate was transferred and diluted with water into $10 \mathrm{~mL}$ in a volumetric flask. This solution is then used for AAS analysis to determine the concentration of the metal ion after adsorption. This procedure was performed three times for each concentration. The correlation of M(II) concentration (ppm) and the adsorption capacity $(\mathrm{mg} / \mathrm{g})$ is presented in a graph with the former as the $x$ axis and the latter as the $y$-axis.

\section{Calculation}

The adsorption percentage was calculated based on equation 1, where Co is the initial concentration before the adsorption and $\mathrm{Cs}$ is the concentration after the adsorption. The adsorption capacity was calculated using equation 2 , where $\mathrm{V}$ is the solution volume in Litre and $\mathrm{W}$ is the chitosan-silica adsorbent mass in gram.

$\% \mathrm{M}^{2+}=\frac{\mathrm{Co}-\mathrm{Cs}}{\mathrm{Co}} \times 100 \%$

Adsorption Capacity $=\frac{(\mathrm{Co}-\mathrm{Cs}) \times \mathrm{V}}{\mathrm{W}} \mathrm{mg} / \mathrm{g}$

\section{Detection Method}

In this work, pH-meter (Mettler Toledo bench-top), drying oven (Memmert), Scanning Electron Microscopy (SEM-Inspect-S50), Fourier-Transform Infrared Spectroscopy (FTIR-8400S) and Atomic Adsorption Spectroscopy (AAS-Shimadzu AA600) were used. FTIR sample was prepared in KBr pellet and the analysis was conducted at $4000-500 \mathrm{~cm}^{-1} . \mathrm{Mn}^{2+}, \mathrm{Cu}^{2+}$ and $\mathrm{Zn}^{2+}$ samples for AAS were analysed using cathode hollow tube lamp with wavelengths of $228.8 \mathrm{~nm}, 248.3 \mathrm{~nm}$, and $213.6 \mathrm{~nm}$, respectively. All works were conducted at room temperature and were mostly done in the Inorganic Chemistry Laboratory of Chemistry Department, Brawijaya University, Indonesia, and the factual room temperature during the batch-adsorption process was recorded around $25-30^{\circ} \mathrm{C}$. 


\section{Preparation and Characterization of Chitosan-Silica \\ RESULTS AND DISCUSSION}

The chitosan-silica used in this work was prepared by sol-gel method, as also reported by Budnyak, ${ }^{13}$ Lalchhingpuii, ${ }^{15} \mathrm{Lai}^{24}{ }^{24}$ and Naat, ${ }^{25}$ except they used a different source of silica. In our work, the chitosansilica was obtained through the hydrolysis of sodium metasilicate in chitosan solution and gives a reasonably good yield. This is because both chitosan and silica were pure chemical grade, different to those reported by Hanandayu, ${ }^{17}$ Sumarni, ${ }^{18}$ and Mahatmanti, ${ }^{19}$ which utilize silica freshly prepared from rice husks. The purity of the precursor affects the quality of the chitosan-silica in which purer chitosansilica contains fewer impurities, and thus increases the adsorption ability of the adsorbent. Sodium metasilicate is also economically affordable.

The silica is attached to the chitosan via ionic interaction between the chitosan ammonium $\left(-\mathrm{NH}_{3}{ }^{+}\right)$ groups and the silica silanol $\left(\mathrm{Si}-\mathrm{O}^{-}\right)$groups. Moreover, hydrogen bonding may also be formed between the chitosan carbonyl $(\mathrm{C}=\mathrm{O})$ groups and the silica hydroxyl $(-\mathrm{OH})$ groups. The adsorption of the metal ion by the chitosan-silica expected to occur through physical (pores of silica) and chemical interactions (functional groups and chelating effect of the adsorbent, ionic charge, and/or HSAB interactions).

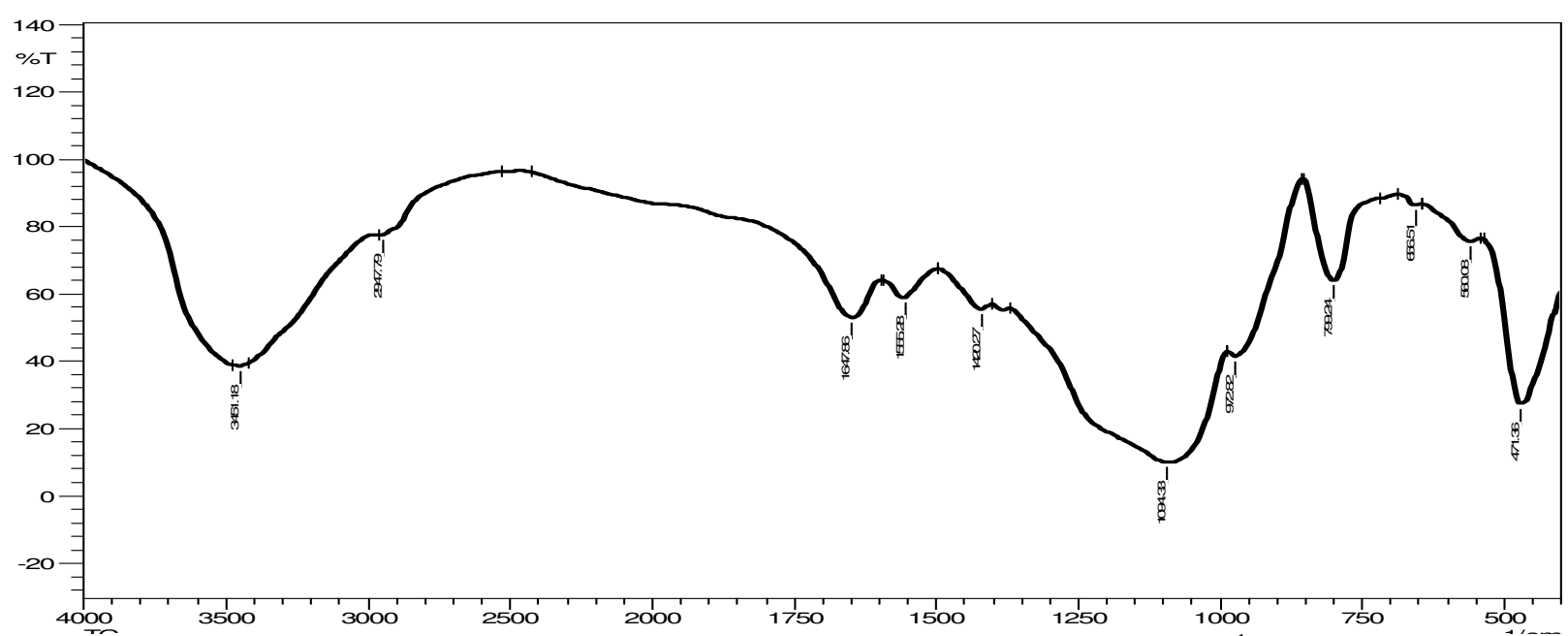

Fig.-2: FTIR Spectra of Chitosan-Silica Prepared in this Work, $\mathrm{x}=$ Wavelength $\left(\mathrm{cm}^{-1}\right)$ and $y=\% \mathrm{~T}$.

The chitosan-silica was characterized by FTIR and SEM before it was used for adsorption. FT-IR spectra of chitosan-silica is presented in Fig.-2, whereas SEM image of chitosan-silica is shown in Fig.-3. FT-IR analysis showed that the chitosan-silica spectra have characteristic peaks as expected in which some of these functional groups may involve in the adsorption, namely broad $\mathrm{O}-\mathrm{H}$ stretch band at $3451.2 \mathrm{~cm}^{-1}, \mathrm{sp}^{3}$ $\mathrm{C}-\mathrm{H}$ stretch peak at $2947.8 \mathrm{~cm}^{-1}, \mathrm{C}=\mathrm{O}$ stretch at $1647.3 \mathrm{~cm}^{-1}, \mathrm{C}-\mathrm{O}-\mathrm{C}$ stretch at $1555.3 \mathrm{~cm}^{-1}, \mathrm{Si}-\mathrm{O}-\mathrm{Si}$ and aliphatic Si-O-C stretch at $1094.3 \mathrm{~cm}^{-1}$, and $\mathrm{Si}-\mathrm{OH}$ stretch at $972.8 \mathrm{~cm}^{-1}$. Meanwhile, the SEM image of the chitosan-silica shows that the adsorbent has a rough surface and irregular block shapes. These results, both FT-IR spectra and SEM image, are identical to those chitosan-silica reported previously. ${ }^{13,25}$

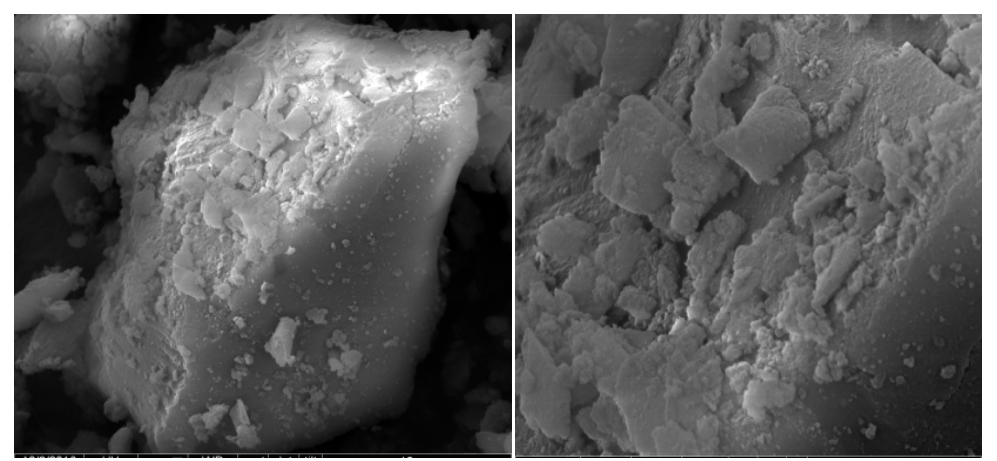

Fig.-3: SEM Images of Chitosan-Silica at a magnification of 7000 (left) and 20,000 (right) 


\section{Determination of Optimum pH}

The solution $\mathrm{pH}$ is crucial in adsorption of metal ion and is the first step to optimize the adsorption process. This is due to the $\mathrm{pH}$ level govern the ionic species distribution in the solution as well as the presence and stability of functional or active groups of the adsorbent. In this work, the adsorption was done in an acid condition ( $\mathrm{pH} 3-6)$ to avoid precipitation of the metal ions. Moreover, high level of acid in the solution ( $\mathrm{pH}$ below 3) will initiate the further reaction with the chitosan-silica, thus affecting the functional groups on the adsorbent and decreasing the adsorption ability of the adsorbent. A further reaction of chitosan-silica in a very high level of acid (low $\mathrm{pH}$ ) will also dissolve the adsorbent into the solution as the adsorbent could be ionized at very low $\mathrm{pH}$.

The effect of $\mathrm{pH}$ in adsorption of $\mathrm{Mn}^{2+}, \mathrm{Cu}^{2+}$, and $\mathrm{Zn}^{2+}$ by chitosan-silica is presented in Fig.-4. In general, the optimum $\mathrm{pH}$ of $\mathrm{M}$ (II) adsorption by chitosan-silica was reached at 5 , in which the highest adsorption percentage was shown by $\mathrm{Cu}^{2+}$, followed by $\mathrm{Mn}^{2+}$ and $\mathrm{Zn}^{2+}$, successively. The adsorption percentages $(\%)$ of $\mathrm{Cu}^{2+}, \mathrm{Mn}^{2+}$ and $\mathrm{Zn}^{2+}$ at $\mathrm{pH} 5$ were $84.98 \pm 0.06,73.04 \pm 9.56$, and $47.46 \pm 0.66$, respectively. The adsorption percentages of all ions are increased steadily from $\mathrm{pH} 3$ to 5 as the concentration of $\mathrm{H}^{+}$in the solution declines. The high concentration of $\mathrm{H}^{+}(\mathrm{low} \mathrm{pH})$ in the solution causes protonation of some of the adsorbent functional groups, hence some functional groups on the adsorbent surface turn into a positive charge. This positive charge resulting in repulsion between the metal ions and the adsorbent, and as a result, only a few amounts of metal ions in the solution were adsorbed.

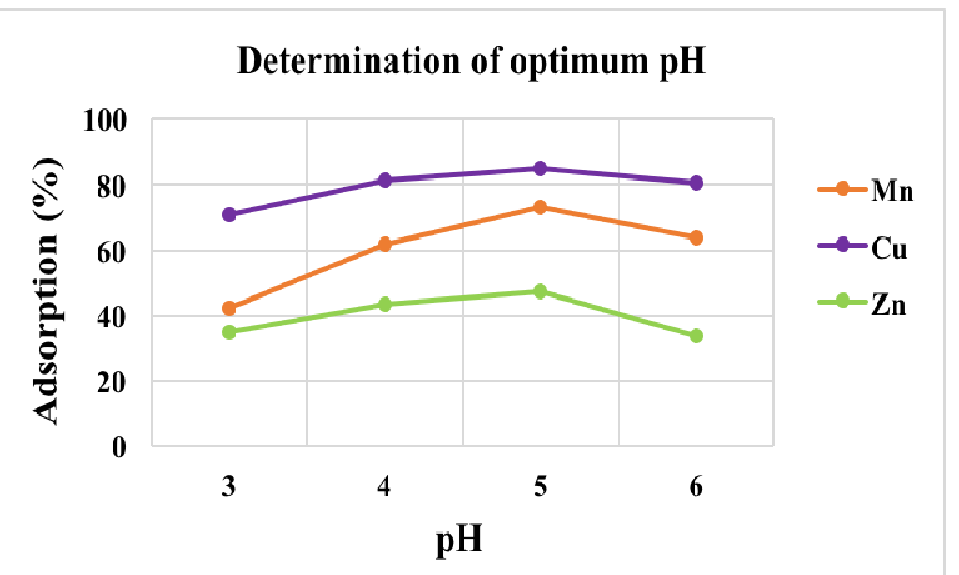

Fig.-4: Effect of $\mathrm{pH}$ in the Adsorption of $\mathrm{Mn}^{2+}, \mathrm{Cu}^{2+}$, and $\mathrm{Zn}^{2+}$ by Chitosan-Silica.

The adsorption percentage of $\mathrm{Cu}^{2+}$ is about $14 \%$ higher than that of $\mathrm{Mn}^{2+}$ and about $90 \%$ higher than that of $\mathrm{Zn}^{2+}$. The metal ion adsorption may take place due to interaction with the functional groups on the adsorbent surface and/or trapped by the adsorbent pores of the silica cross-links because chitosan-silica has a neutral charge in those pHs. In other words, ionic interactions between the adsorbent and the metal ions may not be occurred or have an insignificant effect.

According to HSAB concept, ${ }^{23}$ most of the functional groups on the adsorbent surface are grouped as a hard base, such as the carbonyl $(\mathrm{C}=\mathrm{O})$, oxide $(-\mathrm{O}-)$, and hydroxyl $(-\mathrm{OH})$ groups. These functional groups are expected to have interaction or to form a coordination bond with metal ions. Hence, hard acid $\mathrm{Mn}^{2+}$ and borderline acid $\mathrm{Cu}^{2+}$ will likely form a stronger interaction with the adsorbent than the soft acid $\mathrm{Zn}^{2+}$. If only HSAB concept is applied, hard-hard or soft-soft interactions are preferable and form stronger interaction or bond.

Moreover, the size of metal ion may also have a role in the low adsorption of $\mathrm{Zn}^{2+}$, in which the $\mathrm{Zn}^{2+}$ has the biggest size compared to $\mathrm{Mn}^{2+}$ and $\mathrm{Cu}^{2+}$. Big size ions may not fit or trapped firmly in the chitosansilica pores. Since the size of $\mathrm{Mn}^{2+}, \mathrm{Cu}^{2+}$, and $\mathrm{Zn}^{2+}$ are insignificantly different, ${ }^{22}$ the contribution of size of metal ions toward the adsorption percentage in this work is considerably minor. Therefore, this result indicates that the chitosan-silica is better adsorbent for hard and/or borderline acid metal ions. The adsorption for soft acid such as $\mathrm{Zn}^{2+}$ could be increased if the adsorbent is modified with a soft base such as nitrile or sulphide groups. This optimum $\mathrm{pH}$ is then used in the next stage. 
RASĀYAN J. Chem.

Vol. 12 | No. 3 |1485 - 1492| July - September | 2019

\section{Determination of Optimum Contact Time}

Optimum contact time is needed in order to get a better result as well as time efficiency for the adsorption. When the contact time is too short, the adsorption may not reach its equilibrium and the adsorption results may not be optimum, whereas when the contact time is too long, the system could get saturated and further reaction may occur, hence the adsorption results may be unreliable. Longer time may also mean that the adsorbent may not have good time efficiency.

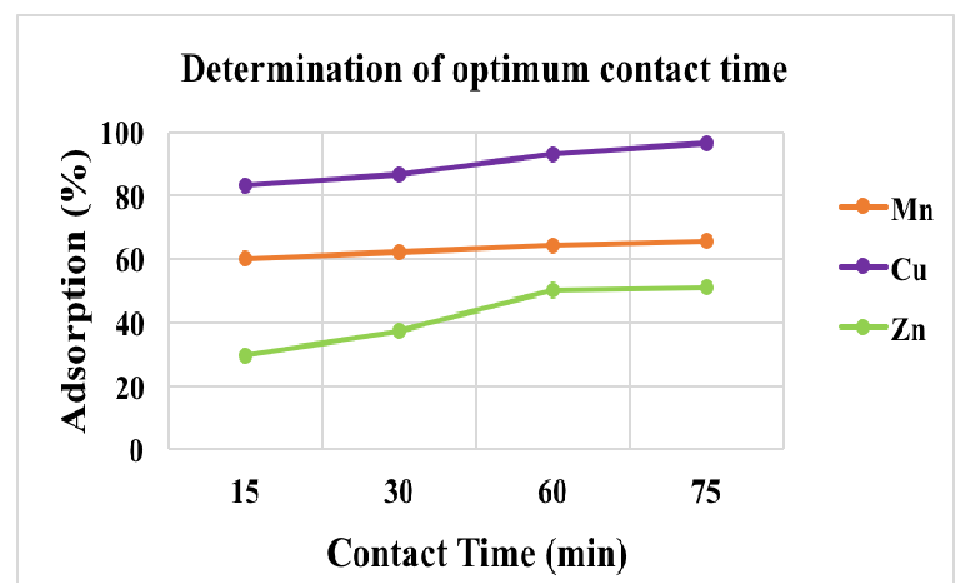

Fig.-5: Effect of Contact Time in the Adsorption of $\mathrm{Mn}^{2+}, \mathrm{Cu}^{2+}$, and $\mathrm{Zn}^{2+}$ at $\mathrm{pH} 5$ by Chitosan-Silica.

Effect of contact time in the adsorption of $\mathrm{Mn}^{2+}, \mathrm{Cu}^{2+}$, and $\mathrm{Zn}^{2+}$ by chitosan-silica is presented in Fig.-5. In general, the highest adsorption percentage was shown by $\mathrm{Cu}^{2+}$, followed by $\mathrm{Mn}^{2+}$ and $\mathrm{Zn}^{2+}$, successively, which is identical to the previous stage (optimum $\mathrm{pH}$ determination). As the contact time increased from 15 to 75 minutes, the adsorption percentages for all ions were also increased steadily. A significant increase was recorded for $\mathrm{Zn}^{2+}$, and the adsorption percentage was doubled at 60 minutes compared to that of 15 minutes.

The optimum contact time for $\mathrm{Mn}^{2+}$ and $\mathrm{Cu}^{2+}$ adsorption was obtained at 75 minutes with adsorption percentages $(\%)$ of $65.60 \pm 0.37$ and $96.61 \pm 0.12$, respectively, whereas $\mathrm{Zn}^{2+}$ adsorption was obtained at 60 minutes with adsorption percentage $(\%)$ of $50.09 \pm 1.20$. Above 75 minutes, the adsorption percentage of $\mathrm{Mn}^{2+}$ and $\mathrm{Cu}^{2+}$ may or may not be increased. However, based on the amount of adsorbent and the M(II) concentration used in this work, contact time above 75 minutes was considered too long and was not investigated due to time inefficiency. Meanwhile, for $\mathrm{Zn}^{2+}$, the adsorption percentage obtained at 75 minutes' show insignificant difference statistically with that of 60 minutes, thus the optimum contact time for $\mathrm{Zn}^{2+}$ adsorption is 60 minutes.

\section{Correlation of M(II) Concentration and the Adsorption Capacity}

Upon optimizing two factors ( $\mathrm{pH}$ and contact time), more reliable adsorption percentages were obtained for all metal ions. At this point, the adsorption capacities for all metal ions were calculated, which are $6.56 \pm 0.04 \mathrm{mg} / \mathrm{g}$ for $\mathrm{Mn}^{2+}, 15.46 \pm 0.02 \mathrm{mg} / \mathrm{g}$ for $\mathrm{Cu}^{2+}$, and $5.01 \pm 0.12 \mathrm{mg} / \mathrm{g}$ for $\mathrm{Zn}^{2+}$. The $\mathrm{Cu}^{2+}$ gives the highest adsorption capacity than the other ions since $\mathrm{Cu}^{2+}$ has properties in between $\mathrm{Mn}^{2+}$ and $\mathrm{Zn}^{2+}$. Combination of both metal ion size and HSAB concept helps $\mathrm{Cu}^{2+}$ trapped in the adsorbent pores firmly and creates stronger interaction with the functional groups within the chitosan-silica adsorbent.

Correlation between $\mathrm{Mn}^{2+}, \mathrm{Cu}^{2+}$, and $\mathrm{Zn}^{2+}$ concentrations and their adsorption capacities is presented in Fig.-6. In general, the higher the M(II) concentration, the higher the adsorption capacity obtained. However, upon increasing the $\mathrm{M}$ (II) concentration tenfold (10x) from 20 to $200 \mathrm{ppm}$, the raising adsorption capacity was varying, which are about 19 times for $\mathrm{Mn}^{2+}, 9$ times for $\mathrm{Zn}^{2+}$, and only 5 times for $\mathrm{Cu}^{2+}$. Surprisingly, at concentrations below $80 \mathrm{ppm}, \mathrm{Cu}^{2+}$ has the highest adsorption capacity, followed by $\mathrm{Zn}^{2+}$ and $\mathrm{Mn}^{2+}$. At concentrations above $80 \mathrm{ppm}$, the result was on the contrary, in which $\mathrm{Mn}^{2+}$ has the highest adsorption capacity, followed by $\mathrm{Zn}^{2+}$ and $\mathrm{Cu}^{2+}$. At $80 \mathrm{ppm}$, the adsorption capacities for $\mathrm{Mn}^{2+}, \mathrm{Cu}^{2+}$, and $\mathrm{Zn}^{2+}$ were considerably equal (about $12 \mathrm{mg} / \mathrm{g}$ ). 
This trend indicates that both metal ion size and HSAB concept have a role on the adsorption capacity when low metal ion concentration was used, which is also observed during the determination of optimum $\mathrm{pH}$ and contact time. On the other hand, upon using high metal ion concentration, it is proposed that the HSAB concept has a more dominant effect on the adsorption capacity since stronger interactions are preferably formed between hard acid $\mathrm{Mn}^{2+}$ and hard base functional groups of the chitosan-silica.

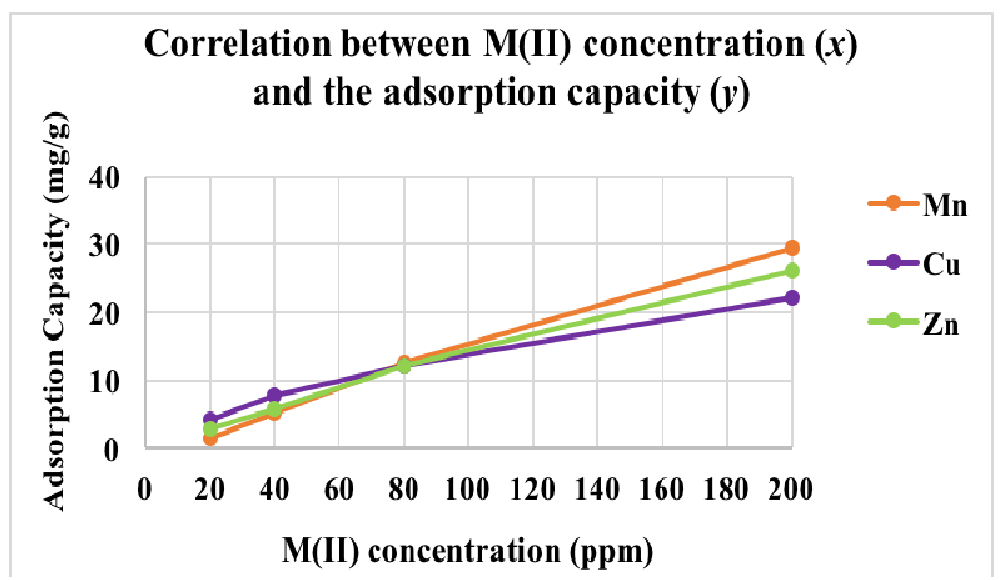

Fig.-6: Correlation between M(II) Concentration ( $x$-axis) and the Adsorption Capacities ( $y$-axis) for Various Metal Ions at Optimum $\mathrm{pH}$ and Contact Time.

Optimum adsorption capacities for all transition metal ions, based on optimum $\mathrm{pH}$ and contact time only, are not reported in this work due to the graph (Fig.-6) has not yet reached an optimum point, as the graph remains increased until $200 \mathrm{ppm}$. The adsorption capacity is the maximum ability of the adsorbent to absorb a soluble suspension. Determination of optimum adsorption capacity of chitosan-silica was done by using a variation of metal ion concentrations $(20-200 \mathrm{ppm})$. For future works, the optimum adsorption capacity can be determined upon increasing the M(II) concentration above 200 ppm until the graph shows an optimum point (or relatively flat line) and the data are tested statistically.

As mentioned earlier in the introduction, this work is an initial stage on the development of chitosansilica as an adsorbent for transition and/or heavy metal ions. The two factors ( $\mathrm{pH}$ and contact time) discussed in this paper are crucial and indeed affecting the adsorption of $\mathrm{Mn}^{2+}, \mathrm{Cu}^{2+}$, and $\mathrm{Zn}^{2+}$ by chitosan-silica adsorbent at room temperature. This result gives baseline information of the future prospect of using chitosan-silica for adsorption of transition metal and/or heavy metal ions in solution waste. However, the adsorption capacities of all metal ions obtained in this work are not final yet and can still be increased. There are other influential factors that have not been incorporated that may increase the adsorption capacity, such as temperature, adsorbent concentration, metal ion concentration, shaking rate, etc. These factors will be investigated and explored in details in future works, including possible functionalization of the chitosan-silica active groups, as well as using other transition/heavy metal ions and/or mixed metal ions solution to study the chitosan-silica selectivity and recovery.

\section{CONCLUSION}

Chitosan-silica was successfully made using sol-gel method and used as an adsorbent for adsorption of $\mathrm{Mn}^{2+}, \mathrm{Cu}^{2+}$, and $\mathrm{Zn}^{2+}$ at room temperature. The FTIR and SEM analyses confirmed that the adsorbent has functional groups, shape, and surface morphology as expected and was identical to related chitosan-silica reported previously. The highest adsorption capacity was obtained by $\mathrm{Cu}^{2+}, \mathrm{Mn}^{2+}$, and $\mathrm{Zn}^{2+}$, successively. The optimum $\mathrm{pH}$ for $\mathrm{Mn}^{2+}, \mathrm{Cu}^{2+}$ and $\mathrm{Zn}^{2+}$ adsorptions was reached at 5. The optimum contact time for $\mathrm{Mn}^{2+}$ and $\mathrm{Cu}^{2+}$ adsorption was obtained at 75 minutes with adsorption capacities of $6.56 \pm 0.04 \mathrm{mg} / \mathrm{g}$ and $15.46 \pm 0.02 \mathrm{mg} / \mathrm{g}$, respectively, whereas $\mathrm{Zn}^{2+}$ adsorption was obtained at 60 minutes with an adsorption capacity of $5.01 \pm 0.12 \mathrm{mg} / \mathrm{g}$. It is suggested that due to the combination of ionic size and HSAB concept, $\mathrm{Cu}^{2+}$ gives the highest adsorption capacity than that of $\mathrm{Mn}^{2+}$ and $\mathrm{Zn}^{2+}$. These adsorption capacities may still be increased by incorporating other influential factors. 
RASĀYAN J. Chem.

Vol. 12 | No. 3 |1485 - 1492| July - September | 2019

\section{ACKNOWLEDGMENT}

All authors thanks and acknowledges the Faculty of Science, Brawijaya University (DPP-SPP Research Grant Scheme - 2017) and the International Scientific Publication Office (PPIKID) of Brawijaya University, Indonesia, for financial support.

\section{REFERENCES}

1. S. Pokhrel, P.N. Yadav, and R. Adhikari, Nepal J. Sci. Technol., 16(1), 99(2015), DOI: 10.3126/njst.v16i1.14363.

2. D. Zvezdova, Sci. Work. Russ. Uni.y, 49(9.1), 65 (2010).

3. P.K. Dutta, J. Dutta, and V.S. Tripathi, J. Sci. Indust. Res., 63, 20 (2004).

4. C. Gerente, V.K.C. Lee, P. Le Cloirec, and G. McKay, J. Critic. Rev. Environ. Sci. Technol., 37(1), 41 (2007), DOI: 10.1080/10643380600729089.

5. G.Z. Kyzas and D.N. Bikiaris, Marine Drugs, 13, 312 (2015), DOI: 10.3390/md13010312.

6. A. Plaza, D. Kolodynska, P. Halas, and M. Geca, Ads. Sci Technol., 35(9-10), 834 (2017), DOI: $10.1177 / 0263617417716367$.

7. M.H. Dehghani, A. Dehghan, H. Alidadi, M. Dolatabadi, M. Mehrabpour, and A. Converti, Korean J. Chem. Eng., 34(6), 1699 (2017), DOI:10.1007/s11814-017-0077-2.

8. U. Habiba, T.A. Siddique, T.C. Joo, A. Salleh, B.C. Ang, and A.M. Afifi, Carbo. Polym., 157, 1568 (2017), DOI:10.1016/j.carbpol.2016.11.037.

9. N.A. Travlou, G.Z. Kyzas, N.K. Lazaridis, and E.A. Deliyanni, Chem. Eng. J., 217, 256(2013), DOI: 10.1016/j.cej.2012.12.008.

10. Darjito, D. Purwonugroho, and R. Ningsih, J. Pure. App. Chem. Res., 3(2), 53 (2014).

11. A. Sabarudin and S. Motomizu, J. Pure. App. Chem. Res., 2(1), 48 (2013).

12. O. Anggraito, A. Sabarudin, and A. Mulyasuryani, J. Pure. App. Chem. Res., 3(2), 47 (2014).

13. T.M. Budnyak, I.V. Pylypchuk, V.A. Tertykh, E.S. Yanovska, and D. Kolodynska, Nanoscale Res. Lett., 10, 87 (2015), DOI: 10.1186/s11671-014-0722-1.

14. S.S. Rashidova, D.S. Shakarova, O.N. Ruzimuradov, D.T. Satubaldieva, S.V. Zalyalieva, O.A. Shpigun, V.P. Varlamov, and B.D. Kabulov, J. Chromatogr. B, 800(1-2), 49(2004), DOI: 10.1016/j.jchromb.2003.10.015.

15. Lalchhingpuii, T. Diwakar, S-I. Choi, Lalhmunsiama, and S-M. Lee, Desal. Water Treat., 101, 232 (2018), DOI: $10.5004 /$ dwt.2018.21745.

16. Tiwari, A.K. and S. Nath, Rasayan J. Chem, 12(1), 73 (2019), DOI: 10.31788/RJC.2019.1213093.

17. H. Widwiastuti, A. Mulyasuryani, and A. Sabarudin, J. Pure. App. Chem. Res., 2(1), 42 (2013).

18. W. Sumarni, R. S. Iswari, P. Marwoto, and E. F. Rahayu, IOP Conf. Series: Mater. Sci. Eng., 107, No. 012039 (2016), DOI: 10.1088/1757-899X/107/1/012039.

19. F.W. Mahatmanti, Nuryono, and Narsito, Indones. J. Chem, 16(1), 45(2016), DOI: 10.22146/ijc.1043.

20. M.A. Mohmed, A. Mulyasuryani, and A. Sabarudin, J. Pure. App. Chem. Res., 2(2), 62 (2013).

21. Muflikhah, B. Rusdiarso, E.G.R. Putra, and Nuryono, Indones. J. Chem., 17(2), 264 (2017), DOI: 10.22146/ijc.22549.

22. A. Blackman and L.R. Gahan, Aylward and Findlay's SI Chemical Data, $7^{\text {th }}$ ed., Wiley, United Kingdom (2013).

23. R. G. Pearson, Chemical Hardness, Wiley-VCH Verlag GmbH, Weinheim, Germany (1997).

24. S.M. Lai, J.M.Y. Arthur, W.C. Chen, and J.F. Hsiao, Poly-Plast Tech. Eng., 45, 997 (2006), DOI: $10.1080 / 03602550600726269$.

25. J.N. Naat, T. Lapailaka, A. Sabarudin, and R.T. Tjahjanto, Rasayan J. Chem., 11(4), 1467(2018), DOI: $10.31788 /$ RJC.2018.1144055.

[RJC-5220/2019] 